Brit. J. vener. Dis. (1956), 32, 137.

\title{
EDITORIAL
}

\section{PROSTITUTION AND VENEREAL DISEASE}

The Special Committee of the British Medical Association, which recently submitted evidence ${ }^{1}$ to the Departmental Committee on Homosexuality and Prostitution, defined female prostitution as habitual consorting with a variety of men for sexual purposes and for gain in money or kind, and Laird, in his article on page 181, also argues that promiscuous women who accept payment in kind rather than in money are prostitutes in effect although not in law.

The Committee expressed the opinion that there was no single cause which determined the behaviour of the prostitute, but rather a multiplicity of causes, each re-inforcing the other. It suggested that in most cases of habitual prostitution there was an innate deviation of temperament amounting to a perversion of the normal female sexual impulse. High on the list of determining factors was an unsatisfactory home background with lack of parental love and security, the parents themselves being in many cases dishonest and amoral, with complete lack of spiritual values or any sense of social responsibility. The girls were apt to be lazy, self-indulgent, and emotionally immature, and they were lured by a desire for excitement and false glamour which persisted beyond the age of adolescence. Many gave the history of minor delinquency and rebellion against authority at home and at school. Evidence of minor degrees of mental deficiency or mental subnormality associated with intellectual inferiority and social inadequacy was present in many cases. Prostitution was, however, a matter which should not be considered only from the angle of the female partner. It was a question of supply and demand and a genuine and serious demand did exist.

Clearly this is not primarily a medical problem, but the physician must be concerned with its causes, prevention and effects, particularly in the spread of infectious diseases.

It is well-known that the incidence of some venereal diseases has diminished in the population generally and probably also among prostitutes. Many attribute this improvement solely to improved methods of treatment due to the introduction of penicillin and other antibiotics; but it is obvious to anyone in close contact with the subject that treatment is only one of a number of factors which influence the rise and fall of the incidence of venereal infections. The standards of diagnosis and treatment and the qualities of the facilities provided for infected patients are certainly very important. This country owes a great deal to the Venereal Diseases Scheme which was inaugurated in 1916 and through the years has provided an easily available, free, and confidential service in which the public has confidence and of which infected patients, including prostitutes, avail themselves very readily. It is a service unsurpassed in the world and it deserves the full support and encouragement of enlightened members of the public, especially in these days when foolish people seek to weaken and destroy it on the grounds that it is expensive and redundant.

It is sometimes said that prostitutes are not now an important cause of the spread of venereal diseases, and one of the reasons given is the insistence of many prostitutes on the use of contraceptive sheaths by their male contacts. This may or may not be true for certain types of prostitutes in certain areas, but the evidence from large clinics for venereal diseases in big cities indicates that prostitutes, including some in organized brothels, are important sources of infection. The British Cooperative Clinical Group, an organization set up by the Medical Society for the Study of Venereal Diseases for the cooperative study of certain problems connected with the subject, collected information ${ }^{2}$ from representative clinics throughout the country, comprising a number of large clinics at major ports, clinics in large industrial cities, four large clinics in London, and a number of smaller clinics in non-industrial towns and rural areas. The information related to 7,157 patients suffering from gonorrhoea, of whom 6,004 were men and 1,153 women. No less than 215 of the infected women admitted that they were prostitutes, and of 5,328 men, who gave information about the source of infection, 1,893 (35.5 per cent.) stated that the infection had been acquired from prostitutes. This appeared to be a particular problem at seaports, where 1,332 of 2,758 infections were acquired from 
prostitutes. There is reason to suppose, therefore, that the seaport prostitute, perhaps repeatedly infected by her overseas contacts, may be a very important source of infection and one of the main reasons for the fact that the incidence of venereal infections has ceased to fall and even, in respect of gonorrhoea, shows a tendency to rise. Laird's figures from two large V.D. clinics in Manchester (see page 181) show that, during the year ending on June 30, 1956, 876 (26 per cent.) of 3,325 men attending for advice had consorted with prostitutes. During this period 30 per cent. of gonococcal infections and 25 per cent. of "non-specific" genital infections were acquired from prostitutes.

It is important to consider what may be done to attack the root cause of this evil which, if one can judge from the numbers of convictions shown in the Annual Reports of the Home Office on Criminal Statistics, is increasing steadily year by year. Society as a whole must certainly take a measure of responsibility for the factors concerned in the problem. It can hardly be denied that the children of this country who attend the non-denominational schools, and that is the great majority, receive at those schools no moral or religious training worthy of the name. This is one reason why marriage has come to be regarded as a temporary arrangement which can be discontinued if difficulties arise, irrespective of the rights and problems of the children of the marriage. Self-interest and materialism are creeds which receive general acceptance, and the status of the family, the unit of Society, is more and more weakened and undermined. A closely related problem is that of housing. In the big cities of this country there are many thousands of people living in appalling and degrading conditions.

The B.M.A. Committee proposed five methods of preventing prostitution:

(1) The development of all social measures which aim at increasing the well-being of the child and the happiness and security of his or her home life.

(2) Parental example and training in self discipline and in social responsibility both in the home and at school.

(3) Improved sex education.

(4) Research into the prevention and treatment of sexual neuroses and perversion.

(5) Strengthening of the law to make it possible for the police to take more active steps to limit and repress the acitivities of those who make money from organized vice.

The last is an important and controversial aspect of this subject. Those who make money from prostitution are the prostitutes themselves and a host of pimps, madames, procurers, landlords, and other less direct participants in the traffic. There is general agreement that severe penalties should be inflicted on those who profit from the earnings of prostitution, whenever they can be convicted, but there is profound and sometimes passionate disagreement as to what should be done about the individual prostitute and how much power should be given to public authorities to control or repress her activities. Advocates of licensed brothels, or other systems involving registration, police supervision, and medical inspections, are always with us, and some of them have been vocal recently. Such proposals are morally reprehensible and, if implemented, would be likely to spread rather than control infectious disease. On the other hand, the B.M.A. Committee felt, and many will agree, that it is of great social importance to make prostitution less obtrusive in big cities and to make communication between the prostitute and the prospective client less easy. It seemed clear that the presence of flagrant prostitution in streets and parks was itself a promoter of the traffic and an active temptation to men of all ages. The potential prostitute was attracted by the prospect of easy money to be earned with impunity. The present situation was an obvious source of scandal, and the young could hardly believe that their elders and those in authority seriously considered prostitution to be wrong or even undesirable when it flourished so obviously and freely.

It is argued that a system of heavy fines or other penalties would, no doubt, drive this traffic off the streets, but would render less accessible the young prostitute who might be reclaimed if known to the authorities. This is probably a valid point, but the scandal of solicitation in the streets of our big cities is so serious that it should be controlled notwithstanding the disadvantages which may result.

The B.M.A. Committee was gloomy about the possibility of helping the confirmed prostitute who is seldom a cooperator, but recommended in respect of young prostitutes:

(1) That they should be taken in charge and brought before the courts as soon as they were recognized by the police. This would involve changes in the law and the provision of more specially trained women police.

(2) That the system of punishment of convicted offenders of any age should be altered to include a period of detention in a special residential establishment. It was thought that the prospect of an ordered, supervised, and hard-working mode of life with some restriction of liberty would be a considerable deterrent to young prostitutes. It was also recommended that facilities for rehabilitation, such as are now being carried out in the best type of Approved Schools, should be available to those over the age of 18. The Committee added, with reason, that long-term after-care and guidance would be 
essential to prevent relapses in the face of subsequent difficulties.

(3) That special care should be given to the selection of staff and to the social help available at clinics for venereal diseases. Contact with these women when they were sick and frightened provided a unique opportunity for rehabilitation.

Proposals of this kind seem reasonable enough to most people in contact with the problem, but they are apt to be received by a display of peculiar emotion by members of some feminist organizations, whose criticism is usually more destructive than helpful. Certainly the last point is worthy of considerable emphasis. It is an unfortunate fact that some clinics for venereal diseases have no social worker, and some social workers in V.D. clinics are over-burdened and receive little encouragement. There is an important field here for social workers of the best type. Unhappily, some of them avoid this work because they know little or nothing about it and it sounds unpleasant. Those who have taken it up have almost invariably found it absorbing and rewarding. As the Committee said, the personal help that can be given by a competent social worker with adequate training and experience in this field is of the greatest value, especially in the follow-up period. It also emphasized that help to be effective should be prompt, private, and uncensorious.

This is a difficult problem and, human nature being what it is, it may be taken as certain that it will never be fully solved. But that is no good reason for the prevailing attitude of laissez faire. The problem presents one of the major social scandals of our times and, from the medical point of view, if the battle against the venereal diseases is ever to be won, here is the next step in the campaign.

\section{REFERENCES}

1"Homosexuality and Prostitution" (1955). British Medical Association. London.

${ }^{2}$ British Journal of Venereal Diseases (1956). 32, 21. 